Check for updates

Cite this: RSC Adv., 2018, 8, 34370

Received 13th September 2018

Accepted 1st October 2018

DOI: $10.1039 / c 8 r a 07639 a$

rsc.li/rsc-advances

\section{Solvent-free hydrogenation of cyclohexene over Rh-TUD-1 at ambient conditions}

\author{
Mhamed Benaissa, (D) a Abdullah M. Alhanash, ${ }^{a}$ Ahmed T. Mubarak, ${ }^{a}$ Morad Eissa, ${ }^{a}$ \\ Taher Sahlabjib and Mohamed S. Hamdy (DD *a
}

Rhodium nanoparticles ( $\approx 3-5 \mathrm{~nm}$ ) were incorporated into the 3D mesoporous TUD-1 material by using sol-gel technique. The prepared catalyst shows high activity in the liquid phase conversion of cyclohexene to cyclohexane at room temperature $(298 \mathrm{~K}), 1 \mathrm{~atm} \mathrm{H}_{2}$ pressure, and under solvent-free conditions. Rhodium nanoparticles exhibited high stability, reusability and negligible leaching.

\section{Introduction}

The hydrogenation of olefins is considered one of the most important reactions in petroleum as well as chemical industries. ${ }^{1,2}$ The hydrogenation of cyclohexene produces cyclohexane, which undergoes oxidation reaction to produce cyclohexanol and cyclohexanone, the precursors of Nylon 6 and Nylon 6,6. ${ }^{3,4}$ Several homogeneous catalysts have been reported to catalyze the liquid phase hydrogenation of cyclohexene, notably Wilkinson type catalysts. ${ }^{5}$ However, due to the industrial problems associated with the use of homogeneous catalysis such as separation and reutilization, the immobilization of homogeneous catalysts on solid supports was targeted., ${ }^{6,7}$ However, the synthesis of these catalysts is normally performed by multi-step procedures which increases the total costs of the overall reaction.

Noble metals attract a lot of interest in heterogeneous hydrogenation reactions due to their high activity. ${ }^{8}$ The catalytic materials which consist of a proper support incorporating highly-dispersed and structurally-defined metallic nanoparticles seem a smart alternative to bulk metal catalysts. ${ }^{9}$ This is because the high surface area of the catalyst and also its low cost compared to the bulk metal catalysts. ${ }^{10}$ Several studies to design heterogeneous catalysts that can activate the cyclohexene hydrogenation have been reported. ${ }^{11,12}$

Rhodium (Rh) is one of the most interesting metal that is used in hydrogenation reactions of olefins either in homogeneous or heterogeneous catalysts. ${ }^{13,14} \mathrm{Few}$ attempts were carried out to hydrogenated cyclohexene to cyclohexane by using supported nanoparticles of rhodium. Crus reported the use of silica supported $\mathrm{Rh}$ particle to hydrogenate cyclohexene in a gas phase, ${ }^{15}$ Dupont and co-workers reported the use of silica

${ }^{a}$ Catalysis Research Group (CRG), Chemistry Department, College of Science, King Khalid University, P. O. Box 9004, Abha 61413, Saudi Arabia.E-mail: m.s.hamdy@ gmail.com

${ }^{b}$ Chemistry Department, College of Science, King Khalid University, P. O. Box 9004, Abha 61413, Saudi Arabia encapsulate $\mathrm{Rh}$ by the help of ionic liquids to hydrogenate cyclohexene at 50 and $70{ }^{\circ} \mathrm{C}^{16}$ On the other hand, Ronzón reported the hydrogenation of cyclohexene over $\mathrm{Rh} / \mathrm{SiO}_{2}$ at room temperature, but they used $\mathrm{H}_{2}$ pressure of $869 \mathrm{KPa} .{ }^{17}$

In the current work, a new catalyst is introduced. The catalyst is made of $\mathrm{Rh}$ nanoparticles incorporated into the threedimensional mesoporous silica TUD-1. The synthesis was carried out by one-pot synthesis procedure based on sol-gel technique very similar to the synthesis method which was reported earlier by Hamdy and coworkers. ${ }^{18-20}$ The activity of the prepared catalyst was investigated in the liquid phase, room temperature $(298 \mathrm{~K})$ and ambient pressure hydrogenation of cyclohexene. The stability and reusability were also investigated.

\section{Experimental}

Nanoparticles of Rh were incorporated into TUD-1 mesoporous silica material by using sol-gel technique. A sample with a $\mathrm{Si} / \mathrm{Rh}$ ratio of 200 was synthesized by using the molar oxide ratio of $1 \mathrm{SiO}_{2}: 0.005 \mathrm{RhO}: 0.5 \mathrm{TEAOH}: 1 \mathrm{TEA}: 15 \mathrm{H}_{2} \mathrm{O}$. In a typical procedure, triethanolamine (TEA, 97\%, ACROS) was diluted by deionized water was added to rhodium(III) nitrate hydrate $\left(\mathrm{Rh}\left(\mathrm{NO}_{3}\right)_{3} \cdot x \mathrm{H}_{2} \mathrm{O}\right.$, Sigma-Aldrich) solution under stirring. The obtained solution was added dropwise to tetraethyl orthosilicate (TEOS, $+98 \%$, ACROS) under vigorous stirring. Then, tetraethyl ammonium hydroxide (TEAOH, 35\%, Aldrich) was added dropwise and the overall mixture was stirred for at least two hours at room temperature. The resulting homogeneous solution/gel was aged at room temperature for $24 \mathrm{~h}$, and then dried at $98{ }^{\circ} \mathrm{C}$ for another $24 \mathrm{~h}$. The obtained brownish solid was grounded and thermally treated in a $50 \mathrm{ml}$ Teflon-lined stainless-steel autoclave at $178{ }^{\circ} \mathrm{C}$ under autogenous pressure for $4 \mathrm{~h}$. The obtained solid was grounded again, and then calcined in static air at $600{ }^{\circ} \mathrm{C}$ for $10 \mathrm{~h}$ by applying a heating ramp rate of 1 degree per min. The obtained material was coded as A-Rh-0.5. Finally, A-Rh-0.5 sample was hydrogenated in 
a tube furnace at $300^{\circ} \mathrm{C}$ for $3 \mathrm{~h}$ to ensure the formation of $\mathrm{Rh}^{0}$ in the final product which coded as Rh-0.5.

XRD was performed by using Schimadzu 6000 DX instrument diffractometer equipped with a graphite monochromator using $\mathrm{CuK}_{\alpha}$ radiation $(\lambda=0.1541 \mathrm{~nm})$. FTIR spectra were collected by using Agilent Cary 630 FTIR Spectrometer. Raman spectrum was collected at ambient conditions by using a Renishaw Raman Imaging Microscope, system 2000. The green $(\lambda=514 \mathrm{~nm})$ polarized radiation of an argon ion laser beam of $20 \mathrm{~mW}$ was used for excitation. Nitrogen adsorption/ desorption isotherms were recorded on a Quanta Chrome NOVA 2000e instrument. The pore size distribution was calculated from the adsorption branch using the Barrett-JoynerHalenda (BJH) model. The BET method was used to calculate the surface area $\left(S_{\mathrm{BET}}\right)$ of the sample. ICP technique was used to quantify the amount of Rh present in the prepared material by using Thermo scientific, ICAP 7000 series, part no: 1340910, Qtegra Soft wear, Germany. Scanning electron microscopy (SEM) Jeol Model 6360 LVSEM, USA, was used to investigate the morphological structure of the prepared sample. Transmission Electron Microscopy (TEM) was carried out on a Philips CM30UT electron microscope with a field emission gun as the source of electrons, operated at $300 \mathrm{kV}$.

The solvent-free hydrogenation of cyclohexene was performed in a stirred batch Parr reactor with $300 \mathrm{ml}$ capacity. Typically, $0.25 \mathrm{~g}$ of the carefully grinded catalyst was placed inside the reactor with $25 \mathrm{ml}$ of cyclohexene ( $\geq 99 \%$, TEDIA, USA). The autoclave was closed and degassed twice with nitrogen and pressurized to the necessary pressure with hydrogen gas. Then, the reaction was vigorously stirred (up to $1000 \mathrm{rpm}$ ) to minimize the external mass transfer limitations. After the reaction time was elapsed, the reactor was flushed with nitrogen and then a liquid sample was withdrawn and filtrated. The concentrations of the product and the reactant were analyzed by using a SHIMADZU GC-17 instrument equipped with RTX-5 capillary column $(30 \mathrm{~m} \times 0.25 \mathrm{~mm} \times 0.25 \mu \mathrm{m})$ and a flame ionization detector (FID).

The conversion of cyclohexene (CXE), was calculated according to the following equations:

$$
\text { Conversion }=\frac{[\mathrm{CXE}]_{0}-[\mathrm{CXE}]_{t}}{[\mathrm{CXE}]_{0}} \times 100
$$

where $[\mathrm{CXE}]_{0}$ is the initial concentration of cyclohexene, $[\mathrm{CXE}]_{t}$ is the concentration of cyclohexene at time $(t)$.

On the other hand, the turnover frequency (TOF) was calculated according to the equation

$$
\mathrm{TOF}=\frac{[\mathrm{CXE}]_{0}-[\mathrm{CXE}]_{t}}{[\mathrm{Rh}] \times \operatorname{time}(\mathrm{s})}
$$

where [Rh] represents the total number of moles of Rh active phase and the reaction time was calculated in seconds.

\section{Results}

ICP elemental analysis showed that the loading $\%$ of rhodium is $0.493 \%$ while the added amount during the synthesis was equivalent to $0.5 \%$. This clearly shows that all the added rhodium amount was found in the final product. Moreover, it also shows the high predictability of the synthesis method.

XRD patterns of Rh-TUD-1 before hydrogenation (A-Rh-0.5) and after hydrogenation (Rh-0.5) are compared with that of neat TUD-1 silica material in Fig. 1A. All the patterns show a broad band around $23-25^{\circ} 2 \theta$ which can be characteristic to amorphous phase of silica. ${ }^{21}$ In the A-Rh-0.5 sample, peaks at $24.4^{\circ}, 32.9^{\circ}, 34.98^{\circ}, 44.0^{\circ}, 48.77^{\circ}, 53.3^{\circ}, 57.17^{\circ}, 61.57^{\circ}$, and $67.54^{\circ} 2 \theta$. These peaks can be attributed to the formation of $\beta$ $\mathrm{Rh}_{2} \mathrm{O}_{3}$ phase (JCPDS 76-0148). ${ }^{22}$ After reduction, Rh-0.5 pattern exhibited only peaks at $41.16^{\circ}, 47.86^{\circ}$, and $70.17^{\circ} 2 \theta$. These peaks are corresponding to the crystal planes of (111), (220), and (220), respectively, which indicating the presence of metallic rhodium $\left(\mathrm{Rh}^{0}\right)$ particles (JCPDS 05-0685).

Fig. 1B showed the FT-IR spectra of neat TUD-1 compared with the as-synthesised Rh-TUD-1 and the final solid product Rh-TUD-1. The bands at $1080 \mathrm{~cm}^{-1}$ and $850 \mathrm{~cm}^{-1}$ are corresponding to the characteristic anti-symmetric vibrations of nonbridging oxygen atoms $\left(\mathrm{Si}^{-} \mathrm{O}^{\delta-}\right)$ of $\mathrm{Si}-\mathrm{O}-\mathrm{H}$ bonds and symmetric stretching vibrations $(\mathrm{Si}-\mathrm{O}-\mathrm{Si})_{\text {sym }}$ of tetrahedral $\mathrm{SiO}_{4}$ structure units. Meanwhile, the band at around $460 \mathrm{~cm}^{-1}$ corresponds to the characteristic tetrahedral bending of $\mathrm{Si}-\mathrm{O}$ bonds. These bands were also observed in A-Rh-0.5 and Rh-0.5 samples in addition to a shoulder at $960 \mathrm{~cm}^{-1}$. This shoulder can be assigned to the vibration of defected $\mathrm{Si}-\mathrm{O}$ as a result of $\mathrm{Rh}$ presence..$^{23,24}$ The intensity of the shoulder is getting intense in Rh-0.5 due to increase the interaction strength between the $\mathrm{Rh}$ nanoparticles and the silica support.

To confirm the transformation of $\mathrm{Rh}_{2} \mathrm{O}_{3}$ in the assynthesised sample to metallic $\mathrm{Rh}$ in the hydrogenated sample, Raman analysis was performed. Raman spectrum of ARh-0.5 is compared with that of Rh-0.5 in Fig. 1C. The spectrum of A-Rh-0.5 is dominated by three bands at around 265, 411, $549 \mathrm{~cm}^{-1}$ which is characteristic to the presence of hexagonal $\beta$ $\mathrm{Rh}_{2} \mathrm{O}_{3}{ }^{25}$ These peaks were totally disappeared after hydrogenation step as an indication for the formation of metallic Rh.
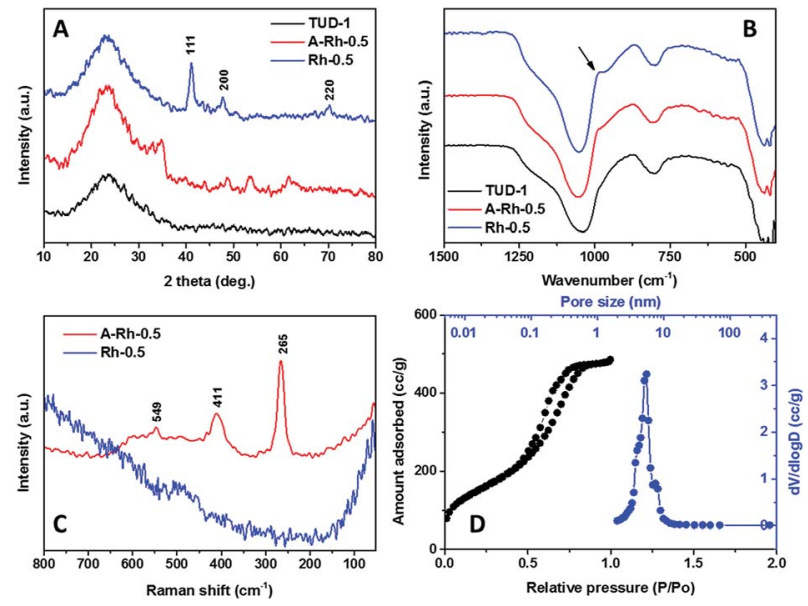

Fig. 1 (A) XRD patterns of the neat TUD-1, as synthetized Rh-TUD-1 (A-Rh-0.5) and Rh-0.5 sample. (B) The corresponding FTIR spectra. (C) Raman spectra of A-Rh-0.5 compared to Rh-0.5 sample. (D) The $\mathrm{N}_{2}$ sorption isotherms of $\mathrm{Rh}-0.5$ sample together with the pore size distribution. 
The $\mathrm{N}_{2}$ adsorption-desorption isotherm of Rh-0.5 sample is presented in Fig. 1D together with the corresponding pore size distribution. The $\mathrm{N}_{2}$ sorption isotherms was found to be type IV and exhibited $\mathrm{H} 1$ type of hysteresis loop which is characteristic to the mesoporous materials. Moreover, BET surface area was found to be $721 \mathrm{~m}^{2} \mathrm{~g}^{-1}$ with an average pore size of $4.8 \mathrm{~nm}$.

In order to investigate the morphological structure of Rh-0.5, SEM analysis was carried out. The SEM micrograph (Fig. 2A) shows the irregular shape of TUD-1 matrix, no other bulky phase was observed. Moreover, EDX analysis exhibited only the peaks of $\mathrm{Si}, \mathrm{O}$ and $\mathrm{Rh}$, which confirms the formation of the catalysts with high purity. The formation of the $\mathrm{Rh}$ nanoparticles was established by HR-TEM analysis (Fig. 2B). The micrograph of Rh-0.5 sample shows the highly dispersed nanoparticles of $\mathrm{Rh}$ incorporated in the mesoporous matrix. Moreover, the average nanoparticle size was measured to be between 3 and $5 \mathrm{~nm}$.

The catalytic activity of Rh-TUD- 1 was investigated in the solvent-free liquid phase hydrogenation of cyclohexene at ambient conditions. Fig. 3A shows the conversion of cyclohexene and the TOF over Rh-TUD-1 catalyst compared with blank reaction and neat TUD-1. Without catalyst, no conversion at all was obtained after 1 h's reaction, same result was obtained with neat TUD-1. However, when Rh-TUD-1 was used to catalyze
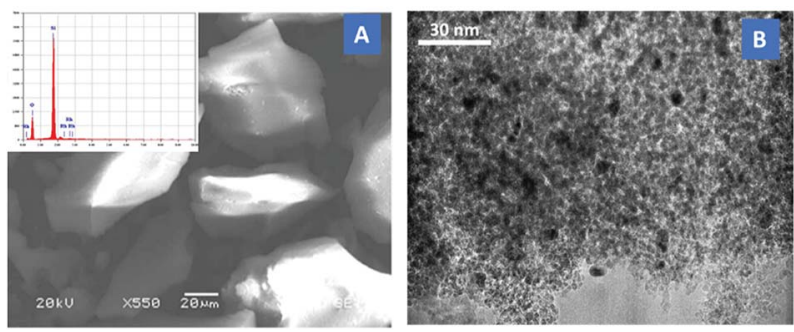

Fig. 2 (A) SEM micrograph of Rh-0.5 sample, inset: the EDX analysis of the sample. (B) HR-TEM micrograph of the Rh-0.5 sample.
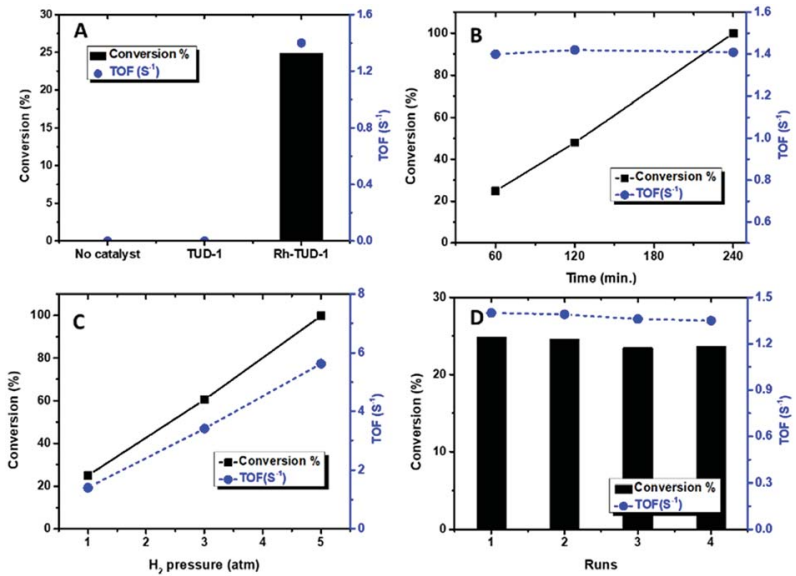

Fig. 3 The conversion\% of cyclohexene and the corresponding TOF over Rh-TUD-1 under ambient temperature and $\mathrm{H}_{2}$ pressure: (A) compared with the blank reaction, (B) at different time up to 4 hours, (C) at different $\mathrm{H}_{2}$ pressure, and (D) in 4 consecutive reactions without treatment. the reaction, $24.8 \%$ conversion was obtained after 1 h's reaction with a total TOF of $1.4 \mathrm{~S}^{-1}$. Increasing the reaction time led to increase the cyclohexene conversion \% almost linearly; i.e. zero order reaction. After $4 \mathrm{~h}^{\prime}$ reaction, cyclohexene was totally converted to cyclohexane (Fig. 3B), with a constant TOF. Increase the $\mathrm{H}_{2}$ pressure in the autoclave prior the reaction to 3 atm showed positive effect on the conversion, where $60.5 \%$ of cyclohexene was converted to cyclohexane with a TOF of $3.4 \mathrm{~S}^{-1}$ and to $100 \%$ conversion with $5.6 \mathrm{~S}^{-1}$ TOF at $\mathrm{H}_{2}$ pressure of 5 atm (Fig. 3C). The recycling of Rh-TUD-1 was investigated through performing four consecutive reaction without any treatment for the catalyst. The obtained results are plotted in Fig. 3D. The results show minor loss in activity from reaction to another with a constant TOF. Similar behavior was also reported by Leshkov and coworkers about the stability of Rh incorporated hydroxyapatite. ${ }^{26}$

To confirm the stability of the Rh-TUD-1 during the hydrogenation of cyclohexene, the used Rh-TUD-1 sample (after 4 consecutive reactions) was characterized by using XRD, SEM and Rh mapping. Fig. 4 shows the obtained characterization data. XRD pattern of the used Rh-TUD-1 sample is almost identical to that of the fresh sample. The intensity and location of the peaks did not alter, and more importantly, no new crystalline phase(s) could be observed as an indication of the high stability of Rh-TUD-1 sample. In the background of the left panel, the SEM micrograph of the used Rh-TUD-1 sample showed the surface of the sample in the normal irregular particle shape characteristic of the TUD-1 samples. Left panel of Fig. 4, shows the mapping of Rh nanoparticles over the surface of used sample. No agglomeration was observed and the Rh nanoparticles still well dispersed and nicely spread out through the sample's surface, which is in agreement with XRD result.

A comparison between the TOF of Rh-TUD-1 and other Rh containing different supports in the cyclohexene hydrogenation is listed in Table 1 . The comparison clearly shows that Rh-TUD1 possess high activity under the ambient operating conditions and under liquid phase condition. This can be explained by using the TUD-1 with its open three-dimensional framework which gives high accessibility of the substrate/product to/from the $\mathrm{Rh}$ active sites. One more advantage of using Rh-TUD-1 can be related to the ease synthesis procedure, i.e. one-step sol-gel technique, more importantly, surface modification and/or ionic liquids were not needed.
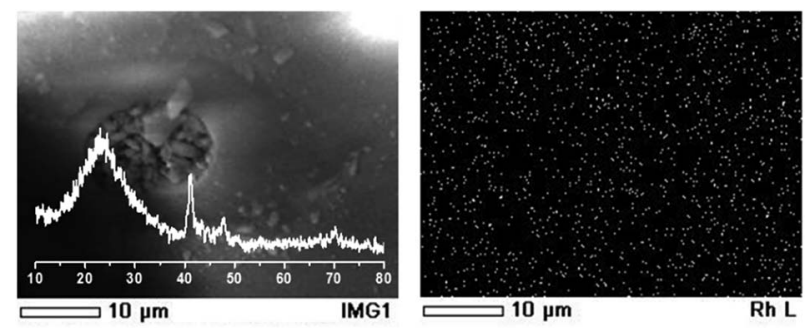

Fig. 4 Left panel: XRD of the used Rh-TUD-1 sample, in the background, a SEM micrograph of the same sample. Right panel: Rh nanoparticles mapping of the used Rh-TUD-1 sample. 
Table 1 Comparison between the activity (represented in TOF) of Rh-TUD-1 and the other reported catalysts

\begin{tabular}{|c|c|c|c|}
\hline Catalyst & TOF $\left(\mathrm{s}^{-1}\right)$ & Conditions & Ref. \\
\hline Rh-TUD-1 & 1.4 & Room $\mathrm{T}, 1 \mathrm{~atm}$, liquid phase reaction, solvent free & $a$ \\
\hline Rh-TUD-1 & 3.4 & Room T, 3 atm, liquid phase reaction, solvent free & $a$ \\
\hline $\mathrm{Rh} / \mathrm{SiO}_{2}$ & 1.7 & Conventional heating, gas phase & 27 \\
\hline $\mathrm{Rh} / \mathrm{SiO}_{2}$ & 1.7 & Room T, $14 \mathrm{KPa} \mathrm{H}_{2}$, gas phase & 28 \\
\hline $\mathrm{Rh} / \mathrm{SiO}_{2} / \mathrm{HF}$ & 0.4 & $70{ }^{\circ} \mathrm{C}, 4$ atm $\mathrm{H}_{2}$, liquid phase & 16 \\
\hline
\end{tabular}

${ }^{a}$ Current study.

\section{Conclusions}

To conclude, $\mathrm{Rh}$ nanoparticles were successfully incorporated into the framework of mesoporous TUD-1 siliceous material. Rh nanoparticles exhibited high activity in the liquid phase, solvent-free hydrogenation of cyclohexene at ambient conditions.

\section{Conflicts of interest}

There are no conflicts to declare.

\section{Acknowledgements}

The authors extend their appreciation to the Deanship of Scientific Research at King Khalid University for funding this work through General Research Project under grant number (G.R.P-199-39).

\section{Notes and references}

1 G. C. Bond and P. B. Wells, Adv. Catal., 1964, 15, 91-226.

2 J. N. Wilson, J. W. Otvos, D. P. Stevenson and C. D. Wagner, Ind. Eng. Chem., 1953, 45, 1480-1487.

3 B. Hereijgers and B. Weckhuysen, J. Catal., 2010, 270, 16-25.

4 I. Berezin, E. Denisov and N. Emanuel, The Oxidation of Cyclohexane, Moscow University Press, Pergamon Press, Oxford, English edition, 1966.

5 J. A. Osborn, F. H. Jardine, J. F. Young and G. Wilkinson, J. Chem. Soc. A, 1966, 1711-1732.

6 E. A. Cagnola, M. E. Quiroga, D. A. Liprandi and P. C. L'Argentière, Appl. Catal., A, 2004, 274, 205-212.

7 M. Pérez-Cadenas, L. J. Lemus-Yegres, M. C. RománMartínez and C. Salinas-Martínez de Lecea, Appl. Catal., A, 2011, 402, 132-138.

8 R. L. Augustine, F. Yaghmaie and J. F. Van Peppen, J. Org. Chem., 1984, 49, 1865-1870.

9 Nanoparticles and catalysis, ed. D. Astruc, John Wiley \& Sons, 2008.
10 M. S. Hamdy, Microporous Mesoporous Mater., 2016, 220, 8187.

11 L. J. Lemus-Yegres, M. Pérez-Cadenas, M. C. RománMartínez and C. Salinas-Martínez De Lecea, Microporous Mesoporous Mater., 2011, 139, 164-172.

12 S. García, R. M. Anderson, H. Celio, N. Dahal, A. Dolocan, J. Zhou and S. M. Humphrey, Chem. Commun., 2013, 49, 4241-4243.

13 H. Hirai, Y. Nakao, N. Toshima and K. Adachi, Chem. Lett., 1976, 5, 905-910.

14 R. R. Schrock and J. A. Osborn, J. Am. Chem. Soc., 1976, 98(8), 2134-2143.

15 G. M. Da Cruz, G. Bugli and G. Djega-Mariadassou, Appl. Catal., 1989, 46, 131-144.

16 M. A. Gelesky, S. S. X. Chiaro, F. A. Pavan, J. H. Z. dos Santos and J. Dupont, Dalton Trans., 2007, 5549-5553.

17 G. Del Angel and E. Ronzón, J. Mol. Catal. A: Chem., 1999, 148, 105-115.

18 M. S. Hamdy and G. Mul, Appl. Catal., B, 2015, 174, 413-420.

19 M. S. Hamdy, M. A. Eissa and S. M. A. S. Keshk, Green Chem., 2017, 19, 5144-5151.

20 M. Benaissa, A. M. Alhanash, M. Eissa and M. S. Hamdy, Catal. Commun., 2017, 101, 62-65.

21 F. Adam, T. S. Chew and J. J. Andas, J. Sol-Gel Sci. Technol., 2011, 59, 580.

22 J. C. Park, Bull. Korean Chem. Soc., 2008, 29, 1787-1793.

23 E. M. Rivera-Muñoz and R. Huirache-Acuña, Int. J. Mol. Sci., 2010, 11, 3069-3086.

24 H. Sun, Q. Tang, Y. Du, X. Liu, Y. Chen and Y. Yang, J. Colloid Interface Sci., 2009, 333, 317-323.

25 W. H. Weber, R. J. Baird and G. W. Graham, J. Raman Spectrosc., 1998, 19, 239-244.

26 M. Zahmakıran, Y. Román-Leshkov and Y. Zhang, Langmuir, 2012, 28, 60-64.

27 N. Dahal, S. García, J. Zhou and S. M. Humphrey, ACS Nano, 2012, 6, 9433-9446.

28 G. M. Da Cruz, Appl. Catal., 1989, 46, 131-144. 